\title{
A case of very late stent thrombosis after sirolimus-eluting stent implantation in a patient with provoked severe coronary spasm
}

\author{
Shigenori Ito*, Masahiko Inomata \\ Division of Cardiology, Nagoya City East Medical Center, Nagoya, Japan \\ Email: *sito@higashi-hosp.jp
}

Received 13 May 2013; revised 3 June 2013; accepted 14 June 2013

Copyright (C) 2013 Shigenori Ito, Masahiko Inomata. This is an open access article distributed under the Creative Commons Attribution License, which permits unrestricted use, distribution, and reproduction in any medium, provided the original work is properly cited.

\begin{abstract}
A 73-year-old male patient suffered from very late stent thrombosis occurred 6 years after sirolimuseluting stent (SES) implantation in the ostial and proximal left anterior descending coronary artery (LAD). He presented emergently with cardiogenic shock and emergent coronary angiography showed thombus in the ostial stent and in the ostial left circumflex artery. Optical coherence tomography found delayed healing on the ostial stent. Acetylcholine provocation test had also shown severe provoked coronary spasm in all coronary arteries 28 months after SES implantation which suggested the association of severe coronary endothelial dysfunction as a potential mechanism of very late stent thrombosis.
\end{abstract}

Keywords: Stent Thrombosis; Drug-Eluting Stent; Coronary Spasm; Coronary Endothelial Dysfunction

\section{INTRODUCTION}

Several mechanisms of very late stent thrombosis (VLST) after drug-eluting stent (DES) implantation have been proposed such as delayed healing $[1,2]$ and/or inadequate intimal coverage [3,4], malapposition [5], low response to antiplatelet agents [6], plaque rupture of in-stent neoatherosclerosis [7], and coronary endothelial dysfunction [8-15]. However, there is still space to be elucidated for understanding the VLST well. Here, we present an interesting case with VLST after sirolimus-eluting stent (SES) implantation which suggests the association of severe coronary endothelial dysfunction as a potential mechanism of VLST.

\footnotetext{
"Corresponding author.
}

\section{CASE}

A 73-year-old man was referred to the previous hospital with chest oppression and cardiogenic shock. A 12 lead electrocardiogram showed ST segment elevation in leads V1-6 and diagnosed as acute ST-segment elevation myocardial infarction. His hemodynamics was collapsed and successfully resuscitated. Nitroglycerine was administrated. Then, he was transferred to our hospital for the interventional treatment. His coronary risk factors were hypertension and former smoking. He suffered from acute coronary syndrome 6 years ago. A SES stent was implanted in the proximal left anterior descending coronary artery (LAD). There was no other significant coronary stenosis. Follow-up coronary angiography, which was performed as a routine work without angina symptoms, showed no abnormality in the stent but acetylcholine provocation test was positive in all coronary arteries in which total occlusion was observed in LAD and left circumflex coronary artery (LCx) 28 months after the SES implantation (Figure 1). He had been well with prescription of aspirin but not thyenopiridine at this presentation. Benidipine and nicorandil had been also prescribed. Emergent coronary angiography revealed subtotal occlusion of both LAD and LCx with thrombus at the ostium (Figure 2). Stent fracture was not observed by angiography (Figure 2) and intravascular ultrasound. Thrombus aspiration was performed with aspiration catheter TVAC ${ }^{\mathrm{TM}}$ (Nipro, Osaka, Japan) followed by insertion of filterwire Filtrap ${ }^{\mathrm{TM}}$ (Nipro, Osaka, Japan) in both arteries. Frequency-domain optical coherence tomography C7 Dragonfly ${ }^{\mathrm{TM}}$ (LightLab, MA, USA) (Figure 3) showed white thrombus on the surface of stent struts in the proximal stent. Almost all of the struts showed intimal coverage except for a few struts with delayed healing in the ostial part where mural thrombus 

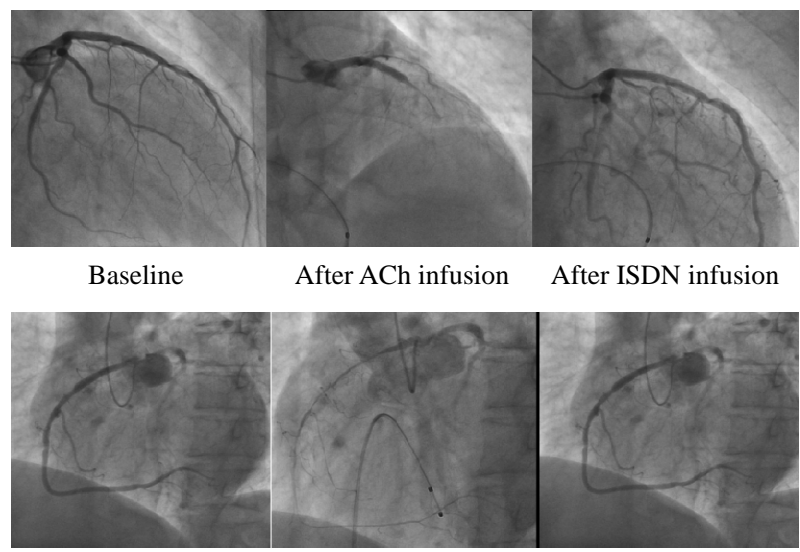

Figure 1. Follow-up coronary angiography 28 months after sirolimus-eluting stent implantation. At control angiogram, there were no significant stenosis or in-stent restenosis. After acetylcholine provocation, severely diffuse spasm with subtotal occlusion was provocated in all coronary arteries.

69 years old Male Cypher for anteroseptal AMI 2006/4/19

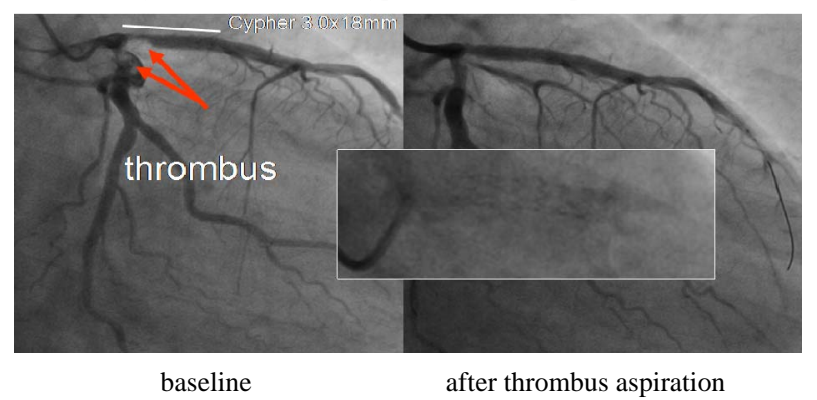

Figure 2. Control coronary angiograms at the index emergent percutaneous coronary intervention. Emergent coronary angiography revealed subtotal occlusion with thrombus in both ostial left anterior descending coronary artery and left circumflex coronary artery. Red arrows indicate thrombus. Magnified delineated box indicates sirolimus-eluting stent without fracture.

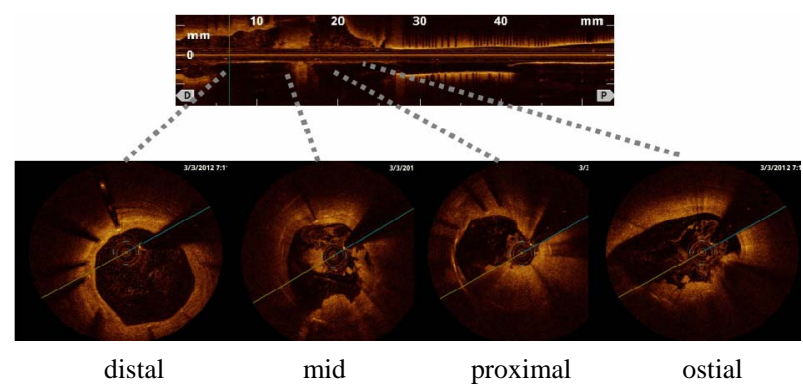

Figure 3. Optical coherence tomography after thrombus aspiration at the percutaneous coronary intervention. White thrombus excisted on the surface of struts in the proximal stent. Struts in the distal part of the stent was covered with intimal hyperplasia but delayed healing was suspected in the ostial part where mural thrombus existed.

existed. There was mild intimal hyperplasia but not ruptured plaque near the thrombus in the proximal segment of LCx by intravascular ultrasound. Nobori ${ }^{\mathrm{TM}}$ stent (Terumo, Tokyo, Japan) was implanted to cover the previous stent crossing over the LCx and post dilatation was performed with kissing balloon technique. Follow-up coronary angiography showed no restenosis or malapposition 8 months later.

\section{DISCUSSION}

In this case, the mechanisms of VLST might have been delayed healing of stent struts in association with coronary endothelial dysfunction. The intimal coverage was detected in almost areas of stent except for the ostium, where mural thrombus existed. In addition to delayed healing of stent struts that has been well known as a cause of VLST [1,2], this case report proposed the severe coronary spasm as an additional mechanism of VLST. Spasm was not detected at the time of emergent angiography probably due to nitroglycerine administration before angiography.

Thrombus was observed in both the ostial LAD and the ostial LCx. We suspect that both thrombus might be formed at the same time due to severe spasm in both LAD and LCx. This patient had no symptoms after SES implantaion for six years. However, late coronary angiography showed severe provoked coronary spasm in all coronary arteries. Coronary spasm has been reported to occur without symptoms $[14,16]$. Thus, we suspect severe coronary endothelial dysfunction might have influence on the occurrence of VLST. Although this patient was prescribed calcium channel blocker and nicorandil after follow-up coronary angiography, dose might have been inadequate to prevent spasm. We can not exclude the possibility that thrombus was initially formed at the ostial LAD followed by migration into the ostial LCX.

Coronary endothelial dysfunction after SES implantation has been reported [8-15]. Acetylcholine provocation or exercise test has revealed vasoconstriction in the segment distal to the implanted stents. In this case provoked spasm was shown in all coronary arteries but not only in stented vessel. Thus, although spasm provocation test was not performed before stent implantation, SES might have exaggerated the spasm severity. The association of coronary vasospasm with SES implantation, which has the possibility of induced endothelial dysfunction, should be cared especially in Asian countries, where a high prevalence of coronary vasospastic angina $[17,18]$ is known, from the standpoint of VLST.

\section{REFERENCES}

[1] Joner, M., Finn, A.V., Farb, A., et al. (2006) Pathology of drug-eluting stents in humans: Delayed healing and late thrombotic risk. Journal of the American College of Car- 
diology, 48, 193-202. doi:10.1016/j.jacc.2006.03.042

[2] Nakazawa, G., Finn, A.V., Joner, M., et al. (2008) Delayed arterial healing and increased late stent thrombosis at culprit sites after drug-eluting stent placement for acute myocardial infarction patients: An autopsy study. Circulation, 118, 1138-1145.

doi:10.1161/CIRCULATIONAHA.107.762047

[3] Guagliumi, G., Sirbu, V., Musumeci, G., et al. (2012) Examination of the in vivo mechanisms of late drug-eluting stent thrombosis: Findings from optical coherence tomography and intravascular ultrasound imaging. JACC: Cardiovascular Interventions, 5, 12-20. doi:10.1016/j.jcin.2011.09.018

[4] Miyazaki, S., Hiasa, Y., Takahashi, T., et al. (2012) In vivo optical coherence tomography of very late drug-eluting stent thrombosis compared with late in-stent restenosis. Circulation Journal, 76, 390-398. doi:10.1253/circj.CJ-11-0961

[5] Cook, S., Wenaweser, P., Togni, M., et al. (2007) Incomplete stent apposition and very late stent thrombosis after drug-eluting stent implantation. Circulation, 115, 24262434. doi:10.1161/CIRCULATIONAHA.106.658237

[6] Breet, N.J., Van Werkum, J.W., Bouman, H.J., et al. (2011) High on-treatment platelet reactivity to both aspirin and clopidogrel is associated with the highest risk of adverse events following percutaneous coronary intervention. Heart, 97, 983-990. doi:10.1136/hrt.2010.220491

[7] Nakazawa, G., Otsuka, F., Nakano, M., et al. (2011) The pathology of neoatherosclerosis in human coronary implants. Journal of the American College of Cardiology, 57, 1314-1322. doi:10.1016/j.jacc.2011.01.011

[8] Togni, M., Raber, L., Cocchia, R., et al. (2007) Local vascular dysfunction after coronary paclitaxel-eluting stent implantaion. International Journal of Cardiology, 120, 212-220. doi:10.1016/j.ijcard.2006.09.021

[9] Hamilos, M., Sarma, J., Ostojic, M., et al. (2008) Interference of drug-eluting stents with endothelium-dependent coronary vasomotion: Evidence for device-specific responses. Circulation: Cardiovascular Interventions, 1, 193-200. doi:10.1161/CIRCINTERVENTIONS.108.797928

[10] Hamilos, M.I., Ostojic, M., Beleslin, B., et al. (2008) On behalf of the NOBORI CORE investigators. Differential effects of drug-eluting stents on local endothelium-dependent coronary vasomotion. Journal of the American College of Cardiology, 51, 2123-2129. doi:10.1016/j.jacc.2007.12.059

[11] Jabs, A., Gobel, S., Wenzel, P., et al. (2008) Sirolimusinduced vasomotor dysfunction increased mitochondrial and nicotinamide adenosine dinucleotide phosphate oxidase-dependent superoxide production and decreased vascular nitric oxide formation. Journal of the American College of Cardiology, 51, 2130-2138. doi:10.1016/j.jacc.2008.01.058

[12] Kim, J.W., Suh, S.Y., Choi, C.U., et al. (2008) Six-month comparison of coronary endothelial dysfunction associated with sirolimus-eluting stent versus paclitaxel-eluting stent. JACC: Cardiovascular Interventions, 1, 65-71. doi:10.1016/j.jcin.2007.11.002

[13] Muhlestein, J.B. (2008) Endothelial dysfunction associated with drug-eluting stent. Journal of the American College of Cardiology, 51, 2139-2140. doi:10.1016/j.jacc.2008.02.057

[14] Ito, S., Nakasuka, K., Morimoto, K., et al. (2011) Angiographic and clinical characteristics of patients with acetylcholine-induced coronary vasospasm on follow-up coronary angiography following drug-eluting stent implantation. Journal of Invasive Cardiology, 23, 57-64.

[15] Minami, Y., Kaneda, H., Inoue, M., et al. (2012) Endothelial dysfunction following drug-eluting stent implantation: A systematic review of the literature. International Journal of Cardiology, 165, 222-228.

[16] Egashira, K., Araki, H., Takeshita, A., Nakamura, M. (1989) Silent myocardial ischemia in patients with variant angina. Japanese Circulation Journal, 53, 1452-1457. doi:10.1253/jcj.53.1452

[17] Beltrame, J.F., Sasayama, S. and Maseri, A. (1999) Racial heterogeneity in coronary artery vasomotor reactivity: Differences between japanese and caucasian patients. Journal of the American College of Cardiology, 33, 1442-1452. doi:10.1016/S0735-1097(99)00073-X

[18] Pristipino, C., Beltrame, J.F., Finocchiaro, M.L., et al. (2000) Major racial differences in coronary constrictor response between japanese and caucasians with recent myocardial infarction. Circulation, 101, 1102-1108. doi:10.1161/01.CIR.101.10.1102 